\title{
UTILITY OF THREE DIMENSIONAL MAGNETIC RESONANCE CHOLANGIOPANCREATOGRAPHY IN EVALUATION OF BILIARY OBSTRUCTION IN ADULTS
}

\author{
Moanes M. Enaba MD *Tarek H. ELKammash **MD, , Mansour M. Morsy ***MD \\ * Department of Diagnostic Radiology, Faculty of medicine, Zagazig University. \\ **Department of Diagnostic Radiology, Faculty of medicine, Suez Canal University. \\ ***Department of General surgery, Faculty of medicine, Zagazig University.
}

\begin{abstract}
Aim: To assess the diagnostic value of 3D MRCP in evaluation of cases with biliary obstruction.

Patients and Methods: 20 patients with clinical suspicion of biliary obstruction were encountered in the study and subjected to imaging assessment including MRI of the abdomen and 3D MRCP.

Results: Our results showed that the commonly affected age group was the group between 28: 38 years old, males were affected more than females, The most common age group in males was $38: 47$ years, while the most common age group in females was $29: 40$ years. The most common clinical findings in our patients was jaundice and biliary colic. Increased total and direct bilirubin was the main laboratory findings in our study. According to the cause of biliary obstruction, 4 patients had benign biliary obstruction $(20 \%), 5$ patients had malignant biliary obstruction $(25 \%), 5$ patients had calcular obstruction $(25 \%)$, and 6 patients had post-cholecystectomy biliary complications (30\%).

Conclusion: 3D MRCP has a main role in evaluation of biliary obstruction and should follow US diagnosed biliary obstruction, replacing the diagnostic role of ERCP and staging role of CT in malignant biliary obstruction.

Keywords: 3D MRCP; Biliary obstruction
\end{abstract}

\section{INTRODUCTION}

M $\mathrm{RCP}$ provides many obvious advantages, regardless the simplicity, and the safety of the technique, it is non-invasive informative study, not requiring ionizing radiation or administration of contrast agents. It has been demonstrated that the clinical value of using MRCP is similar to that of diagnostic direct cholangiopancreatography and in most instances, MRCP will gradually replace direct cholangiopancreatography for diagnostic purposes and provides an efficient alternation when diagnostic ERCP or PTC is unsuccessful or inadequate (1). The threedimensional (3D) MRCP is a sequence that performed in a single breath hold and produces images that are inherently contiguous and registered. These images are thus ideal for multiplanar reformations, and rotating obliquecoronal MIP reconstructions provide good anatomic overview (2). Calculi are the most common surgical causes of the biliary system diseases. Accurate detection of common bile duct (CBD) stones prior to cholecystectomy by MRCP as an emerging radiological tool for evaluation of the biliary tree is mandatory to avoid surgical morbidity associated with residual stones, particularly in the era of laparoscopic biliary surgery(3). Differentiation between benign and malignant strictures in duct is difficult. Benign biliary tumors, stones, strictures, such as an inflammatory stricture secondary to choledocholithiasis, Mirizzi syndrome, extrahepatic localized form of primary sclerosing cholangitis (PSC) and idiopathic benign focal stricture are the possible differential diagnoses of a bile duct carcinoma (4). Various malignant tumors may originate at these sites and show several similarities regarding their clinical presentation which may include biliary obstruction (5). Cholangiocarcinoma and gallbladder carcinoma are the most common primary malignant tumors of the biliary system. Pancreatic cancer is a common cause for malignant biliary obstruction, often associated with dilatation of the pancreatic duct (double-duct sign) (6). Neoplasms arising in the bile ducts and ampulla of Vater pose an important clinical challenge. Although benign neoplasms may be encountered, most of these tumors are malignant (7). MRCP plays a critical role in evaluating alternations in the biliary tract after surgical procedures, it is a rapid, noninvasive, and accurate imaging technique for the assessment of early and late complications of hepatobiliary surgery, it usually enables the identification of normal and abnormal postoperative changes. In cases of complete obstruction of the bile duct, it allows analysis of the biliary tract above and below the level of the obstruction, a capability essential for treatment planning and one that is not provided by either ERCP or PTC (8).

\section{Patients}

\section{PATIENTS AND METHODS}

20 patients with clinical suspicion of biliary obstruction, 12 males (60\%) and 8 females (40\%), their ages ranged between 25 to 50 years old with a mean age of 37 years old. The study was performed during the period from December 
2013 to March 2014. The patients were subjected to the following:

1.Clinical assessment.

2.Imaging assessment:

All patients included in this study were examined using "1.5 tesla superconducting unit" (Achieva, Philips class II a Medical System).

The patient lies supine with the head first on the examination couch. A circular surface coil was used

A- Localizer coronal T1 WI, using the following parameters: Slice thickness 3mm, TR: 320msec,

TE: $17 \mathrm{msec}$, Matrix size: 256x128, NEX: 1 and Time: 28 seconds.

B- Axial T1 weighted FSE images of the upper abdomen using the following parameters: Slice number: 20, Slice thickness: 6-7mm, TR: 500msec, TE: $10 \mathrm{msec}$, Matrix size: 150x256 and NEX: 1.

C-Axial T2 weighted FSE images of the upper abdomen using the following parameters: Slice number: 20, Slice thickness: 6-7mm, TR: 4000msec, TE: $95 \mathrm{msec}$, Matrix size: 150x256 and NEX: 1.

D-Respiratory triggered, three dimensional (3D), MR cholangiopancreatography with MIP reconstruction using the following parameters: Slice number: 15 , Slice thickness: $3: 4 \mathrm{~mm}$, TR: 2000msec, TE: $800 \mathrm{msec}$, Matrix size: 256x256, NEX: $1 / 2$, Scan time: $17 \mathrm{sec}$, Flip angle: $90^{\circ}$ and Field of view: $320 \mathrm{~mm}$.

Multi-section MRCP was performed with respiratory triggering in order to reduce respiratory motion artifacts. The data were acquired between successive respiratory cycles. No specific instructions were given to the patients regarding respiration. Images were obtained in the right anterior oblique plane parallel to the longitudinal axis of the biliary tree. The coronal source images were compressed and reconstructed with maximum intensity projection (MIP) algorithm to create a three dimensional cholangiographic image that could be viewed from multiple angles. Reconstruction was performed; 9-12 oblique images were obtained with frontal to lateral reconstruction at $12^{\circ}-15^{\circ}$ intervals.

\section{Histopathological correlation}

The final diagnosis of the malignant cases was obtained from the pathological results of the sonographic guided fine needle aspiration biopsy in the selected cases.

\section{RESULTS}

According to the cause of biliary obstruction the patients were categorized into 4 groups as in Table (1):
1. Benign obstructive jaundice (4 cases) Table (2).

2. Malignant obstructive jaundice (5 cases) Table (3).

3. Choledocholithiasis (5 cases) Table (4).

4. Post-cholectstectomy biliary complications $(6$ cases) Table (5).

The commonly affected age group was the group between 28: 38 years old, males were affected more than females, The most common age group in males was $38: 47$ years, while the most common age group in females was $29: 40$ years.

4 patients encountered in our study were diagnosed as benign causes of biliary obstruction. One patient with sclerosing cholangitis, one patient with cholestasis, one patient with distal CBD stricture (Fig. 1) and the last one with inspissated bile were diagnosed (table 2).

5 patients encountered in our study were diagnosed as malignant causes of biliary obstruction. 2 patients diagnosed as periampullary carcinoma; 2 patients diagnosed as pancreatic head carcinoma (Fig. 2) and 1 patient diagnosed as Klatskin cholangiocarcinoma (table 3).

5 patients encountered in our study were diagnosed as choledocholithiasis. The site of obstruction was in the CBD in all patients; 4 were in the distal portion of the CBD (Fig. 3) and 1 was in the mid-portion of the CBD. The stones are seen as single or multiple, rounded, oval or faceted signal void filling defects surrounded by high signal intensity bile on T2 WI and 3D MRCP (Fig. 3), associated dilated intra-hepatic biliary radicals (table 4). Abdominal sonography diagnosed only 3 cases, while MRI and 3D MRCP study correctly diagnosed the 5 cases.

6 patients underwent laparoscopic or opened cholecystectomy and presented by postoperative biliary complications were encountered in our study. The diagnosis differ from Smooth post-operative biliary stricture. (2 cases), Passed distal CBD stone/stones. ( 2cases), Ligation of CBD ( one case) ( Fig. 4) and post operative collection in one case. Intra-hepatic biliary radicals dilatations were seen in in all cases (table 5).

Table (6) shows Correlation between US, ERCP, MRI and 3D MRCP in the examined cases where $30 \%$ of cases were diagnosed with abdominal US, $60 \%$ of cases were diagnosed with ERCP and $100 \%$ of cases diagnosed with MRI \& 3D MRCP. 
Table (1): Groups of the examined cases according to the cause of biliary obstruction.

\begin{tabular}{lcc}
\hline \multicolumn{1}{c}{ Items } & No. of cases & $\%$ \\
\hline Benign biliary obstruction. & 4 & 20 \\
\hline Malignant biliary obstruction. & 5 & 25 \\
\hline Calcular obstruction (Choledocholithiasis). & 5 & 25 \\
\hline Post-cholecystectomy biliary complications. & 6 & 30 \\
\hline Total & $\mathbf{2 0}$ & $\mathbf{1 0 0}$ \\
\hline
\end{tabular}

Table (2): Benign causes of biliary obstruction in the examined cases.

\begin{tabular}{llcc}
\hline \multicolumn{1}{c}{ Item } & \multicolumn{1}{c}{ MRI and 3D MRCP findings } & $\begin{array}{c}\text { No. of cases } \\
(4)\end{array}$ \\
\hline Cholestasis. & $\begin{array}{l}\text { Dilated IHBR as well as CBD with no } \\
\text { detectable abnormal SI filling defects, mural } \\
\text { stricture or soft tissue masses. }\end{array}$ & 1 & 25 \\
\hline Inspissated bile. & $\begin{array}{l}\text { Intermediate to low SI seen in the distal CBD, } \\
\text { with proximal biliary dilatation. }\end{array}$ & 1 & 25 \\
\hline Distal CBD stricture. & $\begin{array}{l}\text { Dilated biliary tree proximal to the } \\
\text { obstruction level, with smooth short stricture. }\end{array}$ & 25 \\
\hline Sclerosing cholangitis. & $\begin{array}{l}\text { Multiple strictures and diffuse, irregular } \\
\text { narrowing of IHBR with beaded appearance } \\
\text { and thickened nodular walls. }\end{array}$ & 1 \\
\hline
\end{tabular}

Table (3): Malignant causes of biliary obstruction in the examined cases.

\begin{tabular}{|c|c|}
\hline Peri-ampullary carcinoma (2cases). & MRI and 3D MRCP findings \\
\hline Mass: & $\begin{array}{l}\text { Ill-defined mass in the anatomical site, causing irregular distal } \\
\text { stricture. }\end{array}$ \\
\hline CBD: & $\begin{array}{l}\text { *Abrupt termination of the distal CBD. *Missing segment. } \\
\text { *Irregular filling defect. }\end{array}$ \\
\hline Pancreatic duct: & Normal caliber. \\
\hline IHBR: & $\begin{array}{l}\text { Moderate to severe branching intrahepatic biliary radicals } \\
\text { dilatation. }\end{array}$ \\
\hline Pancreatic head carcinoma (2cases). & MRI and 3D MRCP findings \\
\hline Mass: & $\begin{array}{l}\text { Heterogeneous pancreatic head mass; slightly hypointense on } \\
\text { T1WI and isointense to hyperintense on T2 WI, with } \\
\text { obliteration of the peripancreatic fat. }\end{array}$ \\
\hline$C B D:$ & $\begin{array}{l}\text { *Tapering distal end of the CBD. *Missing segment. *Abrupt } \\
\text { occlusion. }\end{array}$ \\
\hline Pancreatic duct: & Dilated pancreatic duct (Double duct sign). \\
\hline IHBR: & Moderate to severe degree of biliary radicals dilatation. \\
\hline $\begin{array}{l}\text { Klatskin type of cholangiocarcinoma } \\
\text { (1case). }\end{array}$ & MRI and 3D MRCP findings \\
\hline Mass: & $\begin{array}{l}\text { Heterogeneous mass at the confluence of the common hepatic } \\
\text { duct. }\end{array}$ \\
\hline IHBR: & $\begin{array}{l}\text { Markedly dilated intra-hepatic biliary radicals with a stop at } \\
\text { the level of the common hepatic duct. }\end{array}$ \\
\hline
\end{tabular}


Table (4): MRI and 3D MRCP findings in choledocholithiasis.

\begin{tabular}{lcc}
\hline \multicolumn{1}{c}{ Site of CBD stone } & No. of cases(5) & \% \\
\hline Distal portion of the CBD. & 4 & 80 \\
\hline Mid-portion of the CBD. & 1 & 20 \\
\hline \multicolumn{1}{c}{ No. of CBD stone } & 4 & $\%$ \\
\hline Single stone & 1 & 80 \\
\hline Multiple stones & & 20 \\
\hline
\end{tabular}

Table (5): Post-cholecystectomy biliary complications.

MRI and 3D MRCP findings

Dilated intra-hepatic biliary radicals.

No. of cases (6)

Smooth post-operative biliary stricture.

\begin{tabular}{ll}
6 & 100 \\
\hline 2 & 33.3 \\
\hline 2 & 33.3 \\
\hline 1 & 16.7 \\
\hline 1 & 16.7 \\
\hline
\end{tabular}

Passed distal CBD stone/stones.

Ligation of CBD.

Post-operative collection

Table (6): Correlation between US, ERCP, MRI and 3D MRCP in the examined cases.

\begin{tabular}{|c|c|c|c|c|}
\hline Item & $\begin{array}{l}\text { NO. of final } \\
\text { diagnosed }\end{array}$ & $U S$ & ERCP & $\begin{array}{l}\text { MRI and } 3 D \\
\text { MRCP }\end{array}$ \\
\hline & & No. & No. & $\begin{array}{c}\text { No. } \\
\%\end{array}$ \\
\hline $\begin{array}{l}\text { Benign cases of biliary } \\
\text { obstruction }\end{array}$ & 4 & $\begin{array}{l}0 \\
0\end{array}$ & $\begin{array}{l}2 \\
10\end{array}$ & $\begin{array}{l}4 \\
20\end{array}$ \\
\hline $\begin{array}{l}\text { Malignant cases of biliary } \\
\text { obstruction }\end{array}$ & 5 & $\begin{array}{l}1 \\
5.7\end{array}$ & $\begin{array}{l}2 \\
10\end{array}$ & $\begin{array}{l}5 \\
25\end{array}$ \\
\hline Choledocholithiasis & 5 & $\begin{array}{l}3 \\
14.3\end{array}$ & $\begin{array}{l}4 \\
20\end{array}$ & $\begin{array}{l}5 \\
25\end{array}$ \\
\hline $\begin{array}{l}\text { Post-cholecystectomy } \\
\text { complications }\end{array}$ & 6 & $\begin{array}{l}2 \\
11.4\end{array}$ & $\begin{array}{l}4 \\
20\end{array}$ & $\begin{array}{l}6 \\
30\end{array}$ \\
\hline Total & 20 & $\begin{array}{l}6 \\
30 \\
\end{array}$ & $\begin{array}{l}16 \\
60\end{array}$ & $\begin{array}{l}20 \\
100\end{array}$ \\
\hline
\end{tabular}




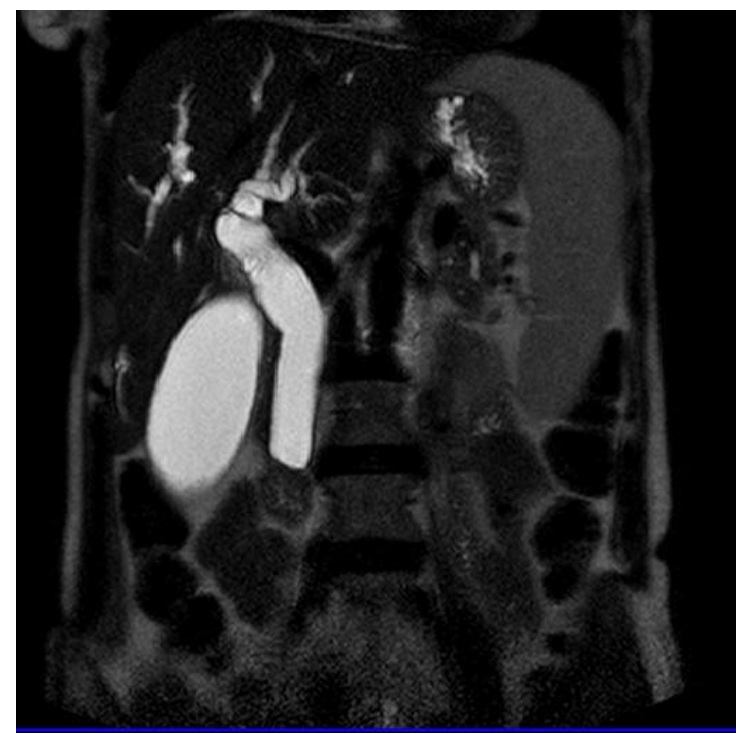

(A)

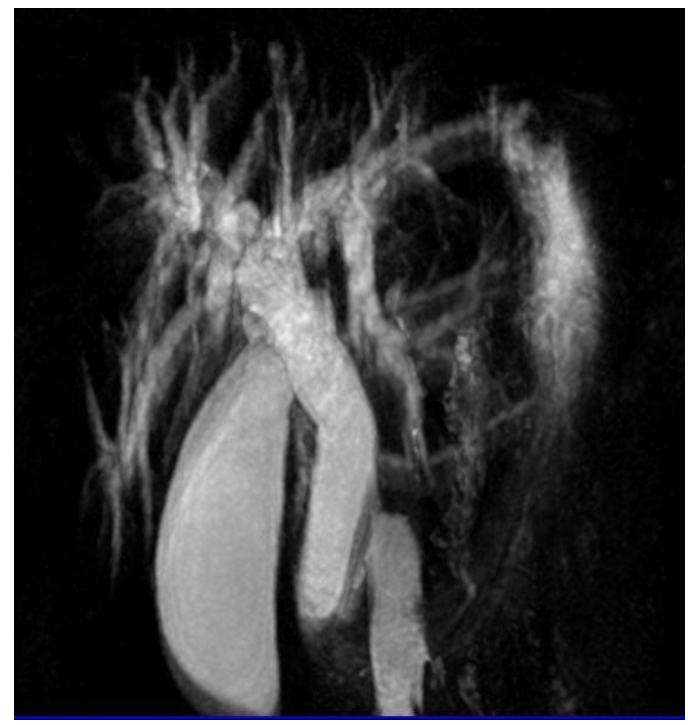

(B)

Fig (1) Benign distal CBD stricture in 35- year-old male, with history of recurrent cholangitis, complained of biliary colic and jaundice. (a) Coronal T2 WI and (b) MRCP revealed significantly dilated IHBR with dilated CBD down to its distal end where there is a smooth short stricture.

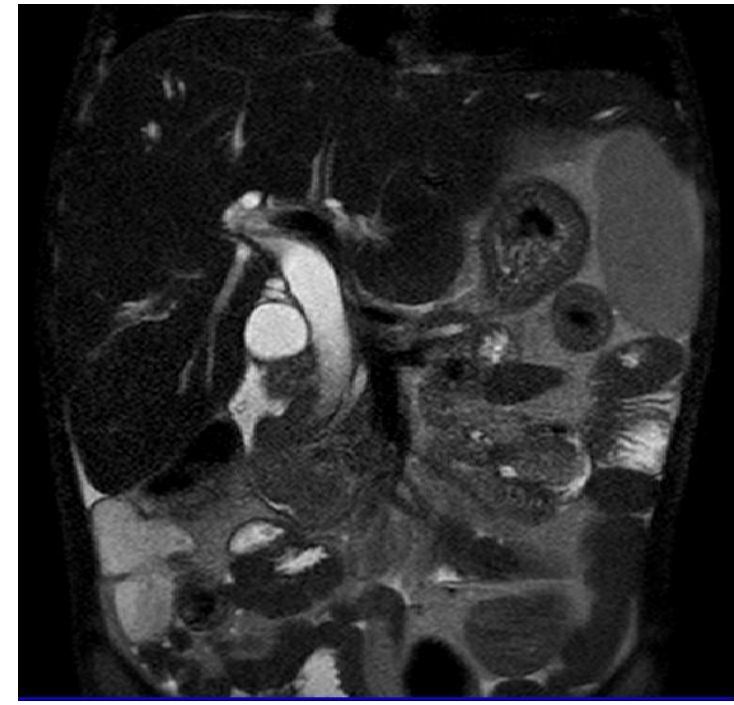

(A)

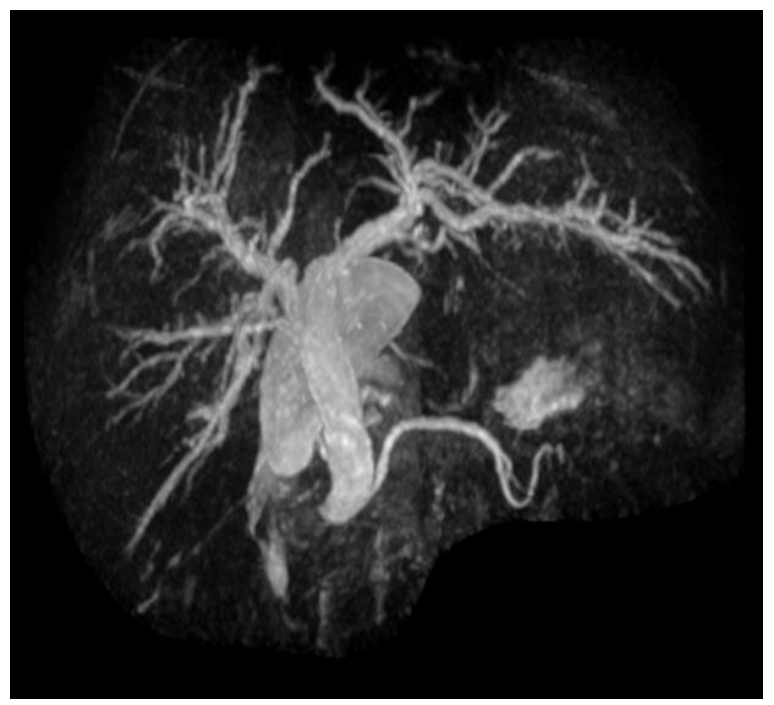

(B)

Fig (2) Pancreatic head carcinoma in an 58-year-old male patient; complained of jaundice, abdominal swelling and cachexia. (a) Coronal T2 WI of the abdomen showed mild degree of IHBR dilatation with mildly dilated CBD down to its distal end with significantly dilated and tortuous pancreatic duct allover its course. An ill-defined heterogeneous SI soft tissue mass is seen at the pancreatic head. (b) 3D MRCP revealed significantly dilated pancreatic duct with irregular distal CBD stricture. 


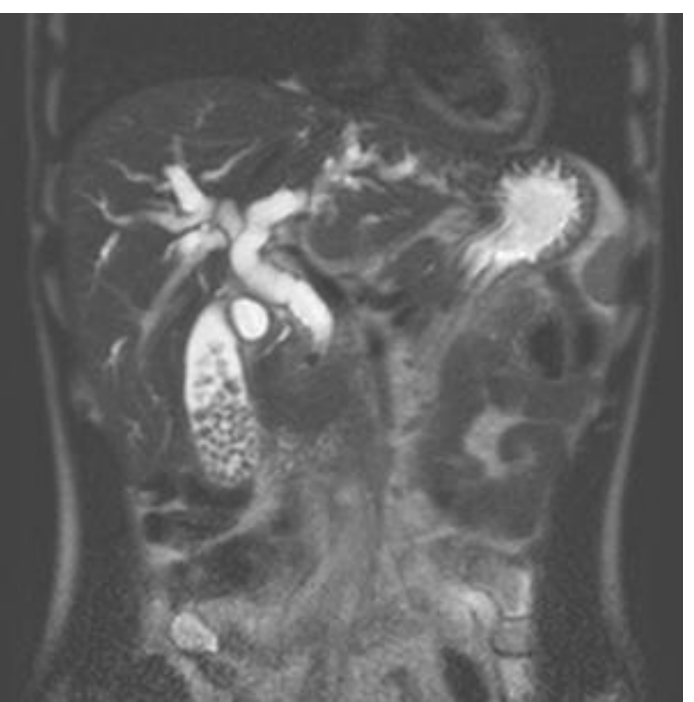

(A)

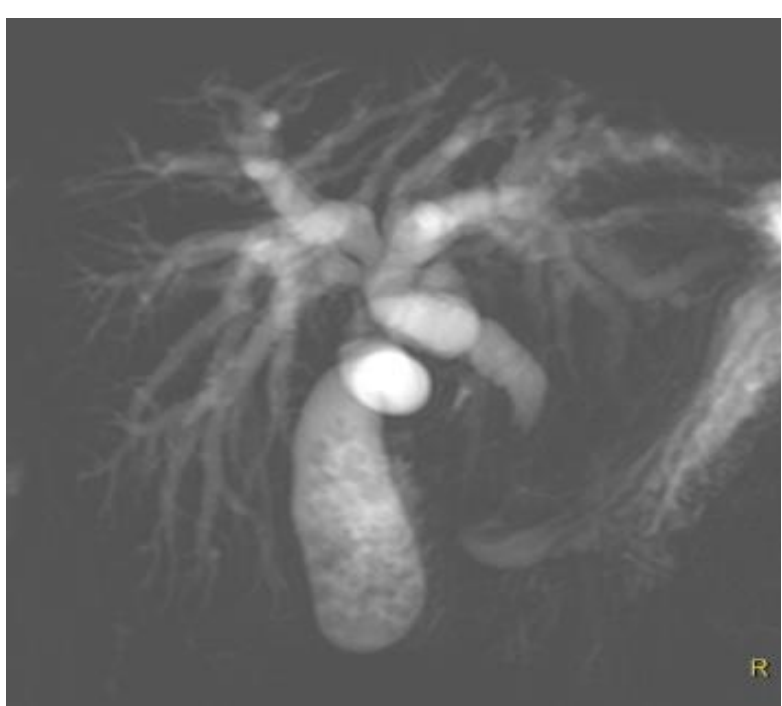

(B)

Fig (3) Single CBD stone (Choledocholithiasis) with calcular cholecystitis in 30-year-old male patient; complained of jaundice, vomiting and biliary colic (a) Coronal T2 WI of the abdomen and (b) 3D MRCP revealed distended GB filled by multiple variable sized hypointense filling defects (stones), associated with marked degree of IHBR dilatation and dilated cystic duct as well as proximal CBD; it harbors a solitary rounded signal void filling defect seen in its mid-portion.

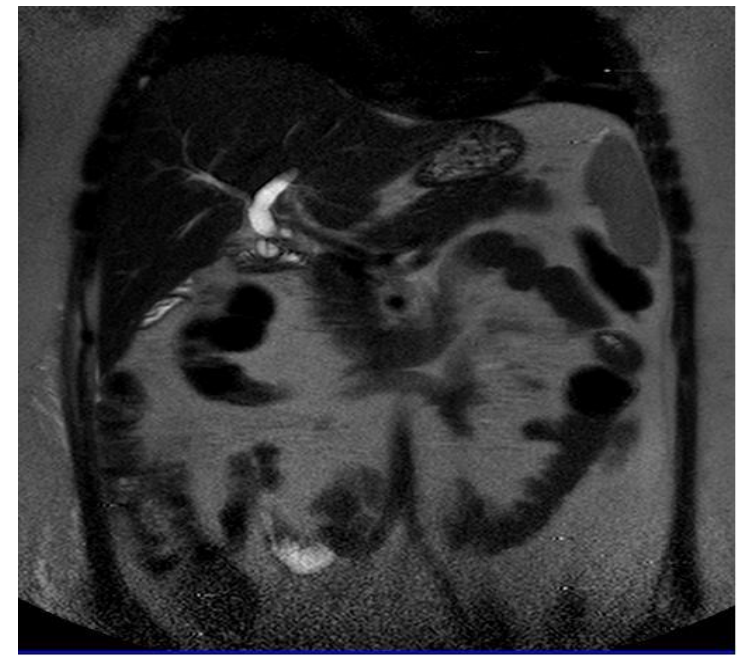

(A)

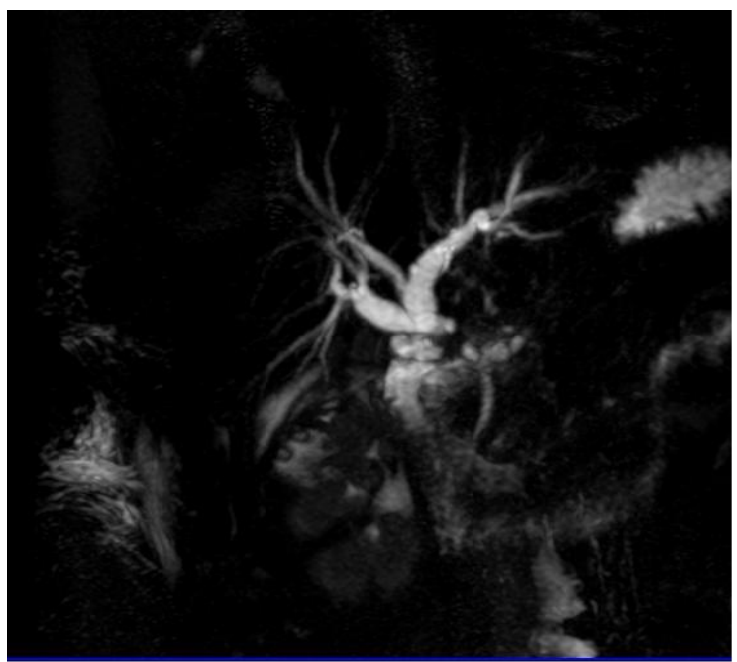

(B)

Fig (3) Post-cholecystectomy iatrogenic CBD ligation in 30-year-old female, underwent opened cholecystectomy 2 weeks ago, complained of biliary colic and jaundice (a) Coronal T2 WI of the abdomen revealed mild degree of IHBR dilatation with dilated proximal course of the CBD. (b) 3D MRCP revealed mildly dilated IHBR with dilated proximal course of the CBD and abrupt termination at which a signal void area of ligation is seen; distal to it the CBD is relatively attenuated.

\section{DISCUSSION}

Erickson and Garza, 2001(9), stated that most algorithms for evaluating biliary obstruction patients recommend clinical and laboratory assessment first, then confirmation of biliary obstruction by using non-invasive imaging methods such as trans-abdominal ultrasound, CT, MRI and MRCP. If these studies were not supportive enough to define the cause of biliary obstruction, then ERCP is recommended to definitively image the biliary tree, obtain a tissue diagnosis if neoplasm is suspected and provide therapy for underlying disorder if appropriate.

Our study included 20 patients with clinical suspicion of biliary obstruction; 12 were males $(60 \%)$ and 8 were females $(40 \%)$, their ages ranged between 25 to 50 years old with a mean age of 37 years old. commonly affected age group was the group between 28: 38 years old, males 
were affected more than females, The most common age group in males was 38 : 47 years, while the most common age group in females was 29 : 40 years. This was in agreement with Kallo and Kantsevory, 2001 (10) who reported that the middle age females are commonly affected by biliary obstruction 2:3 times more than males of the same age group. This was not similar to what described by Varghese et al., 2000 (11) who conducted a similar study on 191 patients, 115 $(60.2 \%)$ were females and $76(39.8 \%)$ were males their ages range 24:92 years old with mean age of 66 years. This discrepancy may be due to small number of patients in our study.

Our patients were categorized according to the cause of biliary obstruction into, 4 patients benign biliary obstruction $(20 \%), 5$ patients malignant biliary obstruction $(25 \%), 5$ patients calcular obstruction (25\%) and 6 patients postcholecystectomy biliary complications (30\%). It was found that stones within the biliary tree are the main cause of obstructive jaundice, these results were as those of Francesco et al., 2005 (12) and Doaa \& Hosam 2010 (13) who mentioned that stones within the biliary tree are the common presentable cause of biliary obstruction and obstructive jaundice.

The typical ductal manifestations for different benign stricture were clearly identified either by presence of smooth short strictures that were the key for diagnosis of benign stricture whatever its cause (recent passage of stone or previous pyogenic cholecystitis), rather than the presence of multiple strictures, diffuse, irregular narrowing of IHD and EHBD that were found in one case of sclerosing cholangitis. Proper easy diagnosis of all biliary strictures were not surprising as many researchers had reported specificity and accuracy of $97 \%$ and $100 \%$, respectively, by using combined conventional MRI and MRCP (14). Our results were in agreement with Dave, 2010 (15) who stated that MRCP has high sensitivity and very high specificity for the diagnosis of sclerosing cholangitis. In many cases of suspected sclerosing cholangitis, MRCP is sufficient for diagnosis, and, thus, the risks associated with ERCP can be avoided. MRCP enabled confirmation of sclerosing cholangitis; in patients with low pretest probabilities, MRCP enabled exclusion of sclerosing cholangitis.

5 patients encountered in our study were diagnosed as malignant causes of biliary obstruction. 2 patients diagnosed as periampullary carcinoma; 2 patients diagnosed as pancreatic carcinoma and Klatskin cholangiocarcinoma in one patient. Our results were as those of Liang et al., 2003 (16) who reported that MRI and MRCP are the most sensitive modality in detecting cholangiocarcinoma. Baron et al., 2002 (14) reported that small masses of distal CBD tumors are extremely difficult to be visualized by US. Han et al., 2002 (17) reported that the role of imaging in cholangiocarcinoma is to assist in the diagnosis and to provide an accurate assessment of surgical respectability

5 patients encountered in our study were diagnosed as cholidocholithiasis. The site of obstruction was in the CBD in all patients; 4 were in the distal portion of the CBD and 1 was in the mid-portion of the CBD. The stones are seen as single or multiple, rounded, oval or faceted signal void filling defect surrounded by high signal intensity bile on T2 WI and MRCP, associated with proximal dilated intra-hepatic biliary radicals. Our results were the same as Doaa and Hosam, 2010 (13), who stated that MRCP is now commonly used as a non-invasive diagnostic tool in many patients suspected of having biliary stones. For patients with obstruction of the biliary ducts; MRI and MRCP can be used to establish the presence and severity of biliary and pancreatic ductal dilatation, detect the length of the stone as well as the exact location of it.

6 patients underwent laparoscopic and opened cholecystectomy and presented by postoperative biliary complications were encountered in our study. These complications included smooth post-operative biliary stricture in 2 patients, passed distal CBD stone/stones in 2 patients, papillary obstruction in 1 patient, postoperative $\mathrm{CBD}$ ligation in 1 patient and postoperative collection in 1 patient. Our results were in agreement with Hoeffel et al., 2006 (8) who concluded that MRCP is a safe and effective method for assessing postoperative alterations in the biliary tract. MRCP has been shown to be comparable with ERCP in demonstrating the location and extent of strictures of the extrahepatic bile duct, with sensitivities of $91 \%-$ $100 \%$ (18 \&19).

Compared to ERCP, 3D MRCP takes a few minutes, usually without sedation. Whenever, no therapeutic intervention is found to be necessary, MRCP avoids the potential morbidity and mortality associated with ERCP. MRCP is particularly useful where ERCP is difficult, hazardous or impossible. It is also an important option for patients with failed ERCPs. (20). The main limitations of MRCP include artifacts such as body (respiratory) movements, presence of 
surgical metallic clips, stents and intestinal or intra-biliary gas (20).

In conclusion, MRI and 3D MRCP should be the next step following suspicion of biliary obstruction by US, replacing the diagnostic role of ERCP and staging role of CT in malignant biliary obstruction in a non-invasive manner; consequently in the near future there will be no place for diagnostic ERCP which will be restricted to the therapeutic applications.

\section{REFERENCES}

(1) Reinhold C, Bret PM. (2006): Current status of MR cholangiopancreatography. Am J Roentgenol;166:1285-95.

(2) Aaron Sodickson, MD, PhD, Koenraad J. Mortele, MD, et al , (2006):

Three-dimensional Fast-Recovery Fast Spin-Echo MRCP: Comparison with Two-dimensional Single-Shot Fast Spin-Echo Techniques. Radiology Volume 238, Issue 2

(3) Hochwald SN, Dobryamky M, Rofsky NM, et al., (2008): MRCP accurately predicts the presence or absence of choledocholithiasis. J Gastrointest Surg;2(6):574-9.

(4) Hadjis NS, Collier NA, Blumgart LH (2005): Malignant mass at the hilum of the liver. $\mathrm{Br} \mathrm{J}$ Surg;72:659-6.

(5) Schwartz LH, Coakley FV, Sun Y, et al., (2008): Neoplastic pancreaticobiliary duct obstruction: evaluation with breath-hold MR cholangiopancreatography. Am J Roentgenol;170:1491-5.

(6) Rosch T, Meining A, Fruhmorgen S, et al., (2002): A prospective comparison of diagnostic accuracy of ERCP, MRCP, CT, and EUS in biliary strictures. Gastrointest Endosc;5:870-6.

(7)Moon SG, Han JK, Kim TK, et al., (2003): Biliary obstruction in metastatic disease: thin-section helical CT findings. Abdomen Imaging;28:45-52.

(8)Hoeffel C., Azizi L., Lewin M., et al., (2006): Normal and pathologic features of the postoperative biliary tract at 3-D MR cholangiopancreatography and MR imaging. RadioGraphics; 26:1603-20.
(9)Erickson Richard A. and Garza Aldo A. (2001): EUS with EUS-guided fine needle aspiration as first endoscopic test for the evaluation of obstructive jaundice, American Society for gastrointestinal Endoscopy, 53, April, 1509-20.

(10)Kallo AN, Kantsevory SV (2001): Gallstones and biliary diseases. W.B. Saunders Company, Primary care, Clinics in office Practice, 28, Sep: 44-9.

(11)Varghese JC, Farrel MA, Courtney G, et al., (2000): A prospective comparison of MRCP with ERCP in evaluation of patients with suspected biliary tract disease, Clin.Radiol, 54: 513-20.

(12)Francesco SF, Federica F, Laurat, et al., (2005): US, MRCP, CT and ERCP. A comparative study in 131 patients with suspected biliary obstruction, Diagnostic Med. Tech. - Sci Minit, 11 (3): 8-18.

(13)Doaa IH, Hosam NA (2010): Magnetic resonance cholangiopancreatography in conjunction with 3D for assessment of different biliary obstruction causes, Egy. J. Radio. Nucl. Med., 41: 483-89.

(14)Baron RL, Mitchell ET, Mark SP (2002): Imaging the spectrum of biliary tract disease, Radiologic clinics of North America, 40: 1325-54.

(15)Dave M (2010): Primary sclerosing cholangitis: meta-analysis of diagnostic performance of MR cholangiopancreatography, Radiology, 256 (2): 387-96.

(16)Liang Z, Qiu YY, Lei L et al., (2003): Imaging diagnosis of pancreatobiliary diseases. A control study. World J. Gastroenterology, 56: 1830-44.

(17)Han Jk, Choi BI, Kim AY, et al., (2002): Cholangiocarcinoma: Pictorial essay of CT and cholangiographic findings, Radiographics, 22:173-87.

(18)Hall-Craggs MA, Allen CM, Owens CM, et al., (2003): MR cholangiography: clinical evaluation in 40 cases, Radiology, 189: 423-27.

(19)Ishizaki Y, Wakayama T, Okada Y, et al., (2003): Magnetic resonance cholangiography for evaluation of obstructive jaundice, Am J Gastroenterol, 88: 2072-77.

(20)Reinhold C, Bret PM (2009): Current status of MR cholangiopancreatography, Am J Roentgenol, 166: 1285-95. 